
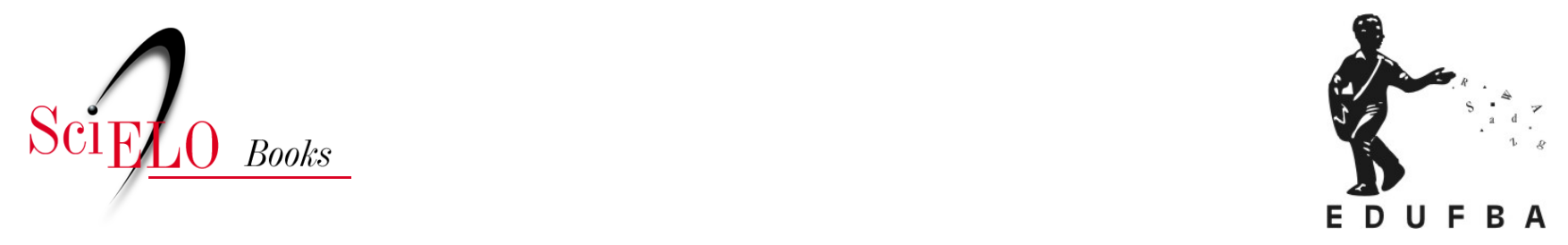

\title{
Compras Coletivas
}

uma análise exploratória de sua utilidade para as empresas anunciantes

\author{
João Renato de Souza Coelho Benazzi \\ Bruno Yagelovic Pedra
}

\section{SciELO Books / SciELO Livros / SciELO Libros}

BENAZZI, J.R.S.C., and PEDRA, B.Y. Compras Coletivas: uma análise exploratória de sua utilidade para as empresas anunciantes. In: RIBEIRO, J.C., FALCÃO, T., and SILVA, T. orgs. Midias sociais: saberes e representações [online]. Salvador: EDUFBA, 2012, pp. 153-173. ISBN 978-85-232-1734-1. Availablefrom: doi: 10.7476/9788523217341.009. Also available in ePUB from:

http://books.scielo.org/id/hcmrr/epub/ribeiro-9788523217341.epub

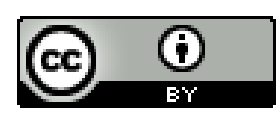

All the contents of this work, except where otherwise noted, is licensed under a Creative Commons Attribution 4.0 International license.

Todo o conteúdo deste trabalho, exceto quando houver ressalva, é publicado sob a licença Creative Commons Atribição 4.0.

Todo el contenido de esta obra, excepto donde se indique lo contrario, está bajo licencia de la licencia Creative Commons Reconocimento 4.0. 


\title{
Compras Coletivas: uma análise exploratória de sua utilidade para as empresas anunciantes
}

\author{
João Renato de Souza Coelho Benazzi \\ Bruno Yagelovic Pedra
}

Introdução

Em uma sociedade cada vez mais competitiva, com rápido acesso à informação e diversos novos meios de comunicação, as organizações estão cada vez mais dispostas a inovar para chamar a atenção dos públicos alvo para seus produtos/serviços. Percebemos também que novos meios de comunicação e propaganda surgem buscando aumentar o contato dos clientes com as empresas. Nessas condiçóes, aproveitando o avanço da internet, surge no Brasil uma modalidade de negócio denominada "compra coletiva", através do site Peixe Urbano (Blog do e-commerce, 2011). Compra coletiva é uma modalidade de e-commerce que tem como objetivo vender produtos e serviços, por um preço abaixo do normal, para um número mínimo pré-estabelecido de consumidores por uma oferta específica. Por meio deste comércio, os compradores geralmente usufruem da mercadoria/serviço apenas após um determinado número mínimo de interessados aderir à oferta para compensar os descontos oferecidos, que podem chegar a até $90 \%$ de seu preço habitual. Por padrão deste mercado os consumidores dispõem de um tempo limite para adquirir à oferta, que varia entre 24 horas e 48 horas após seu lançamento no site. Caso não 
atinja o número mínimo de pedidos dentro deste intervalo de tempo, a oferta é cancelada. Esta ferramenta de e-commerce funciona como forma de divulgação para que empresas exponham seus produtos/ serviços na internet, buscando atrair novos clientes, através de ganho em escala. Por se tratar de um modelo de negócios novo, tendo pouco mais de um ano no Brasil, pouco se sabe sobre seu futuro ou mesmo suas consequências atuais para as partes envolvidas. É a partir desse cenário que iremos à busca de uma resposta: As empresas que anunciam nesses sites de compras coletivas de fato obtêm os benefícios que elas almejam? Até que ponto?

Para atingir tal objetivo, o presente estudo volta-se para a análise das três maiores empresas de compra coletiva com atuação no estado do Rio de Janeiro, são elas: Peixe Urbano (www.peixeurbano.com.br), Groupon, presente no Brasil através do site Clube Urbano (www.groupon.com.br), e ClickOn. ${ }^{1}$ Juntas, estas organizações estão presentes em 107 municípios do Brasil. (THE BEST, 2010)

Esse sistema de promoção possui três partes importantes, são elas: os sites que fornecem a plataforma para o anúncio, as empresas que anunciam seus produtos/serviços e os clientes que fazem a compra dos bens nas plataformas dos sites. Este estudo focará unicamente as empresas que anunciam nos sites, visto que estas são a peça de ligação entre o site e os consumidores finais nesse modelo de negócios, e é preciso uma atenção especial a tais empresas, pois são elas que têm mais a ganhar ou perder com a promoção, dependendo de como a mesma seja realizada. Adicionalmente, se a experiência do cliente com as empresas anunciantes não for satisfatória e o mesmo acontecer em larga escala, todo o modelo de negócio estará comprometido.

<www.clickon.com.br> 


\section{Compras Coletivas: Conceito e origem do modelo de negócios}

O conceito da chamada compra coletiva, via internet, se assemelha ao tradicional cupom de desconto, adaptado a uma forma inovadora de comunicação, comercialização e distribuição das ofertas. A funcionalidade dos sites de compras coletivas se dá quando um anunciante contrata um site para promover certo bem. Para fazer a compra o internauta precisará preencher um cadastro que possibilitará a realização da compra e o manterá informado sobre ofertas do site. Os mesmos efetuam o pagamento on-line por meio de cartão de crédito ou sistemas on-line, como o PagSeguro ou o Mercado Pago, que permitem a transferência de fundos através de um endereço de e-mail, funcionando como um agente que facilita compras e transferências na internet em ambiente seguro. A maior parte das páginas coloca ainda um contador à disposição que informa quantos clientes já compraram a oferta. Quando o número mínimo, pré-determinado pela empresa anunciante, não é alcançado, a promoção é cancelada e os pagamentos devolvidos. Após o anúncio ser feito, a empresa anunciante recebe geralmente $50 \%$ do valor dos cupons vendidos, o restante vai para os sites. É válido lembrar que os anunciantes não recebem o valor logo depois da oferta, uma parte é recebida em 30 dias e outra somente 60 dias depois, e tudo de acordo com o uso efetivo dos cupons. Ou seja, em alguns serviços a receita dos cupons não utilizados fica com o site que divulga a oferta.

Esse modelo de negócio se aproveita da chamada compra por impulso. Rook (1987, p. 191) define que a compra impulsiva ocorre

quando o consumidor experimenta uma necessidade repentina, persistente e muitas vezes poderosa de comprar algo imediatamente. Esse impulso de compra é hedonicamente complexo e pode estimular conflitos de natureza emocional, com reduzida preocupação com suas consequiências de compra. 
Beatty e Farrel (1998) completam o conceito, indicando que essa compra ocorre sem intenções prévias de adquirir algum produto ou de efetuar alguma tarefa de compra, não se constituindo em aquisição de um item lembrado. O modelo é reforçado pelos descontos oferecidos nos sites de compras coletivas. O conceito de compra coletiva começou nos EUA em 2008, com Andrew Mason, criador do Groupon, primeiro site de compras coletivas, que o define como:

O Groupon é um incentivo para levantarmos do sofá e experimentarmos algo excitante em nossas cidades e com as pessoas que gostamos. Mas a grande surpresa para mim foi o imenso apetite dos pequenos negócios por novos consumidores. $\mathrm{E}$ isso foi essencial para o nosso sucesso. Atendemos aos anseios dos consumidores, mas também dos estabelecimentos, 97\% das empresas querem fazer novas ofertas conosco. (BLOG DO E-COMMERCE, 2010)

O site já está próximo de faturar US\$ 1 bilhão em 2011, de acordo com Finkle (2010). Se isso ocorrer, a empresa entrará para a história do mundo corporativo como a que mais rápido ultrapassou o primeiro bilhão. Marca semelhante só foi atingida pelo YouTube.

Segundo Todeschini (2010), a estratégia criada por Mason tira proveito de duas tendências do comportamento do internauta: a pesquisa por barganhas e a participação em redes sociais, cada vez mais crescentes no Brasil. Um link que conecta o site com redes sociais, como Twitter e Facebook, faz com que cada oferta logo seja disseminada pela rede. Desde a fundação já foram feitas mais de 12 milhões de transações nos 29 países onde atua, segundo Todeschini (2010). "O grande apelo do nosso site é que todos ganham, nós ganhamos a comissão, os clientes pagam menos pelo produto e os parceiros conseguem um retorno em larga escala para seus serviços ou produtos". Ainda de acordo com Mason, o Brasil é hoje um dos cinco principais mercados da empresa, caminhando para se tornar em breve o segundo maior, atrás apenas dos Estados Unidos, país de origem do site. Mason ainda define o setor 
de compras coletivas como a melhor forma de propaganda para um negócio local. Segundo ele, "nunca houve nada, seja rádio, televisão, jornais ou até mesmo o gigante Google, tão eficiente em atrair novos consumidores como nós". (TODESCHINI, 2010)

O mercado de compras coletivas no Brasil surgiu no início de 2010 com a criação do Peixe Urbano, e dados do e-bit 2011 nos mostram que o número de sites do gênero chegou, em janeiro de 2011, a mais de mil. (SCHNOOR, 2011) Esse rápido crescimento se dá pelo alto nível de lucratividade do negócio, segundo Vitulli (2011). Em 2010 os sites de compra coletiva tiveram um faturamento superior a US\$ 500 milhões. Segundo Vitulli (2011), citando o Ibope Nielsen on-line, esse segmento chegou a registrar 5,6 milhões de usuários únicos durante o mês de setembro de 2010, o que corresponde a $14 \%$ dos usuários de internet no Brasil. Segundo pesquisa realizada pelo e-bit, entre os dias 10/03/2011 e 14/03/2011, com 4.536 pessoas, foi constatado que entre os consumidores que tiveram experiências com compras coletivas, $82 \%$ pretendem voltar a consumir por esse canal nos próximos três meses. Ao mesmo tempo, 58\% dos entrevistados que ainda não acessaram esse serviço pretendem adquirir seu cupom pela primeira vez. A pesquisa ainda apurou que as três marcas mais lembradas pelo consumidor foram Peixe Urbano, Groupon e ClickOn. Cerca de $80 \%$ das pessoas pesquisadas lembraram ou realizaram compras nestes sites. Macário (2010) projeta para o setor uma incorporação dos pequenos e médios sites de compras coletivas pelos grandes sites, já que, para o lojista, o grande atrativo de sua exposição no site é a visibilidade de sua empresa, que se dá diante do número de acessos diários que o site recebe. Sites menores tendem a perder espaço para os já consolidados no mercado. Segundo Callegari (2011), a aparição dos sites de compra coletiva com foco em nichos de mercado tende a se acentuar. Atualmente já vemos sites voltados para pet shops, mercado rural, hoteleiro e até de cursos on-line. 


\section{Marketing de Serviços e seus Desafios de Comercialização}

De acordo com Kotler e Armstrong (2006, p. 98), a definição de serviço é: "qualquer ato ou desempenho, essencialmente intangível, que uma parte pode oferecer a outra e que não resulta na propriedade de nada. A execução de um serviço pode estar ou não ligada a um produto concreto". De acordo com a hipótese aqui adotada, a venda dos serviços representa parte significativa no setor de compras coletivas. A prestação de serviços tem peculiaridades que devem estar sempre sendo atentadas para que a qualidade do serviço não venha a sofrer muitos desníveis. Tomando por base que os serviços sofrem variações sempre que são prestados, o gerenciamento da qualidade é um ponto fundamental em que as empresas devem sempre se focar. Existem algumas práticas, segundo Kotler e Keller (2006, p. 408), desempenhadas por empresas que gerenciam seus serviços com excelência. São elas: concepção estratégica; comprometimento da alta gerência com a qualidade; padrões rigorosos; tecnologia de autoatendimento; sistemas de monitoramento do desempenho dos serviços; atendimento às reclamações dos clientes; ênfase na satisfação tanto dos clientes como dos funcionários. (BATESON; HOFFMAN, 2001) É fundamental a análise dos erros e acertos presentes para uma melhora futura, assim como estar sempre atento à qualidade dos serviços prestados, ouvindo as reclamaçôes e sugestôes dos clientes para poder agregar valor à empresa. É também importante levar em conta os aspectos tangíveis que podem agregar valor aos serviços, como as tecnologias de autoatendimento e sistemas de monitoramento, que juntos buscam oferecer padrões aos serviços. Devemos salientar que, como o funcionário é o canal direto de comunicação da empresa de serviços com o cliente, a empresa deve atentar não somente para o marketing externo, mas também para o marketing interno, fortalecendo seus laços com os funcionários. (GRONROOS, 2009) 
Ao analisarmos essas práticas percebemos o quão importante é a preparação das empresas que anunciam em sites de compra coletiva. No momento em que a demanda tende a crescer de forma rápida e por um determinado período de tempo, devido aos cupons que foram vendidos, é fundamental que a gerência esteja alerta à qualidade dos serviços para preservar a boa imagem da empresa, com a intenção de que os clientes tenham interesse de voltar, mesmo sem o desconto do site. Visto que os clientes formam expectativas sempre que consomem um serviço, os mecanismos de controle servem para garantir a qualidade e não decepcionar os clientes. Essas expectativas podem vir a partir de diversas fontes, experiências anteriores, propaganda bocaa-boca, dentre outras. Em geral elas são comparadas com o serviço fornecido, caso o mesmo tenha um impacto menor que o esperado pelo cliente, e este pode perder o interesse pelo fornecedor. Caso o serviço iguale ou supere as expectativas, o cliente tende a voltar e consumir o serviço novamente. Geralmente, empresas bem sucedidas adotam em suas estratégias benefícios que não só satisfaçam como também surpreendam positivamente os clientes. Um modelo formulado por Parasuraman, Zeithaml e Berry (1985, p. 407) destaca as exigências mais importantes para a prestação de serviços de qualidade. Existem lacunas ao longo do processo, que são fundamentais para entender os fatores que podem gerar insatisfação nos clientes. O primeiro gap (ou lacuna) se dá entre as expectativas do consumidor e as percepções da gerência, pois nem sempre é entendido corretamente o que de fato os consumidores querem. No segundo vemos o gap entre as percepções da gerência e as especificaçôes da qualidade dos serviços, isso porque os desejos dos clientes podem ser entendidos, mas podem ocorrer falhas na hora de estabelecer um padrão de desempenho. Em seguida temos a diferença entre as especificações de qualidade de um serviço e sua entrega, neste ponto o treinamento da equipe é de fundamental importância, visto que é esta que entregará o serviço. O quarto gap se dá pela diferença entre a entrega do serviço e o modo pelo qual é 
feita a propaganda do mesmo, sendo importante que ambos estejam alinhados para não causar decepção quando um consumidor vir a utilizar o serviço. $\mathrm{O}$ quinto e último gap ocorre quando o cliente não percebe a qualidade do serviço.

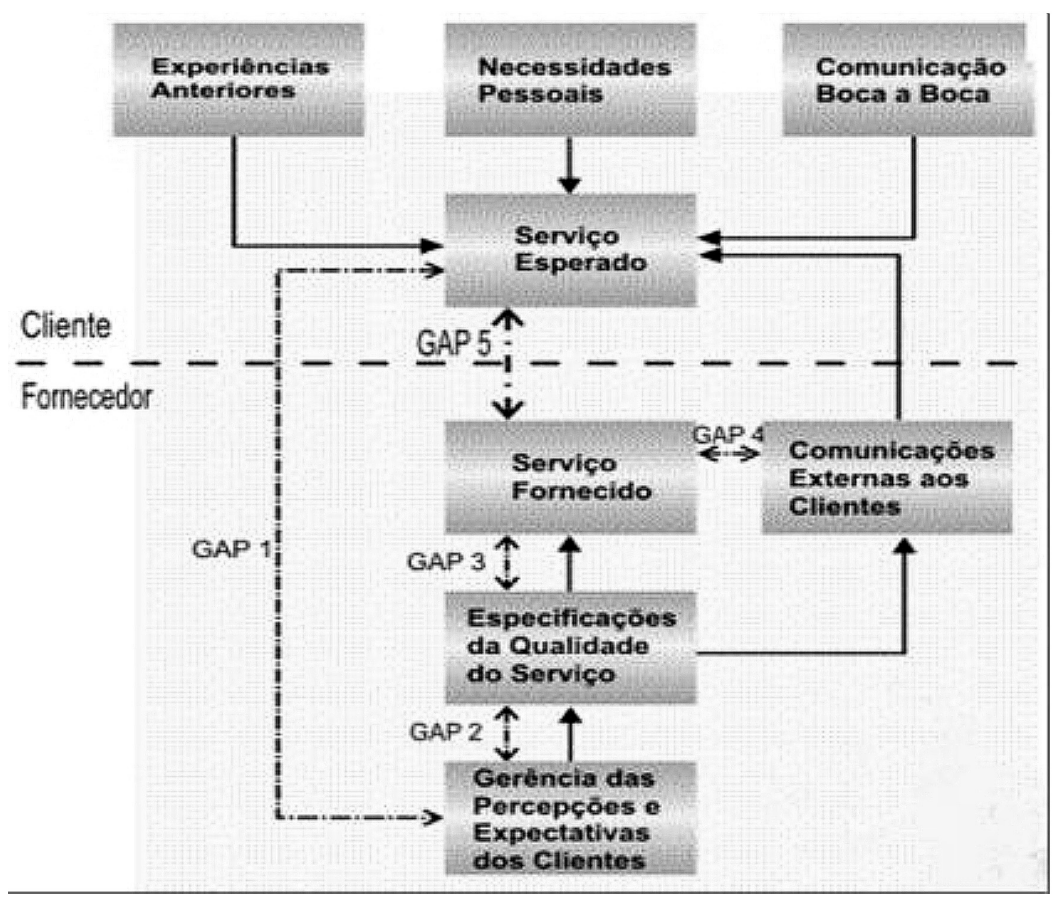

Figura 1 - Modelo dos GAP's de serviços.

Fonte: Parasuraman e outros (1985)

Com base nesse modelo, os pesquisadores puderam identificar cinco fatores que são determinantes na qualidade de um serviço. São eles: a) Confiabilidade - Prestar o serviço assim como prometido; b) Capacidade de Resposta - Disposição para ajudar o cliente e fornecer o serviço no prazo estipulado; c) Segurança - Capacidade dos funcionários de passar segurança e confiança aos clientes; d) Empatia - Atenção individualizada despendida aos clientes; e e) Itens tangíveis - Aparência das instalações e funcionários na prestação do serviço. Com base nesses fatores, Parasuraman, Zeithaml e Berry (1992) desenvolveram uma escala onde se pode observar uma zona de tolerân- 
cia ou uma faixa na qual a percepção dos consumidores é considerada satisfatória, comparando um nível mínimo de aceitação e as expectativas do serviço.

\section{Reclamações sobre os Serviços de Compra Coletiva}

$\mathrm{O}$ rápido crescimento do segmento de sites de compras coletivas gera problemas, e o principal é que alguns padróes de qualidade podem passar despercebidos e o modelo acabar se desviando do propósito inicial. (MACÁRIO, 2010) Muitos clientes reclamam que sentem preconceito por parte dos estabelecimentos quando apresentam os cupons de desconto conquistados através dos sites. (ARAÚJO, 2011) Segundo Oscar (2011), os fornecedores são alvos de queixas por não haver preparo para atender à demanda de cupons, ou seja, vendem mais do que podem entregar/fornecer em um curto espaço de tempo. Ainda de acordo com Sá (2011), consumidores têm se sentido discriminados pelos próprios comerciantes que usam sites de compras coletivas para divulgar produtos e serviços. Foram, em 2010, no total, 3.391 queixas sobre as principais empresas que atuam no setor, como ClickOn, Clube Urbano, Imperdivel, Oferta Única e Peixe Urbano. Há ainda reclamações referentes às cobranças em duplicidade e à dificuldade encontrada por clientes na hora de cancelar ou agendar uma aquisição. Neste caso, um dos principais objetivos do anúncio pode não funcionar. $\mathrm{O}$ fato de um comerciante querer atrair clientes para o seu estabelecimento com uma margem de lucro abaixo da habitual reflete na esperança do cliente se sentir confortável em seu estabelecimento e voltar mais vezes pagando o preço normal. No momento que esse cliente tem suas expectativas frustradas, seja por um mau atendimento ou dificuldade de agendar seu cupom, o mesmo dificilmente voltará ao local.

Segundo Menezes (2010b), existem alguns passos que as empresas devem seguir para poder obter um resultado satisfatório com os 
anúncios. São eles: escolher os produtos mais promissores para promoção; contratar um site de compra coletiva; definir os parâmetros da campanha; e preparar-se para atender a demanda mantendo o padrão de qualidade. Para maximizar o retorno da oferta, deve-se anunciar bens que possam ser vendidos com um desconto expressivo, mas sem prejuízo para a empresa. Além disso, produtos de consumo geral tendem a ser mais bem sucedidos que produtos de nicho, tendo em vista o grande volume de audiência. A disponibilidade de bens complementares àquele que está em promoção também é um fator que aumenta o retorno da campanha. A empresa deve levar em conta qual o produto que a diferencia da concorrência e qual que ela tem maior facilidade de produzir em larga escala. Tomando como exemplo um restaurante, deve-se verificar qual o prato com maior facilidade de fabricação e com boa aceitação da clientela.

Ainda segundo Menezes (2010a), as empresas anunciantes devem procurar contatar e orçar pelo menos três empresas de sites de compras coletivas de diferentes portes e avaliar as propostas. $\mathrm{O}$ valor cobrado pelas empresas de compras coletivas geralmente varia de 30\% a $50 \%$ do valor do bem, mas deve-se observar nesta escolha a visibilidade que aquele determinado site possui, pois é através disso que a oferta terá maior divulgação ou não e, portanto, maior impacto positivo para a empresa anunciante. Definida esta etapa, empresa e site, juntos, definirão os parâmetros da campanha. Nesse planejamento devem constar: data da oferta; quantidade de cupons que poderão ser vendidos; bem a ser ofertado, entre outros atributos da oferta. Não é porque o bem foi vendido a um preço menor que a qualidade do produto ou atendimento deva ser alterada. $\mathrm{O}$ consumidor on-line não deixará de ser exigente só porque comprou com desconto. Além disso, os compradores decorrentes da promoção são potenciais clientes em ocasióes subsequentes e, portanto, devem receber o que a empresa oferece de melhor para que, ao saírem satisfeitos, possam voltar ao estabelecimento pagando o preço normal e recomendar a outros clientes o produto/serviço consumido. 
Tomando por base as análises teóricas sobre o tema deste estudo, entende-se que realmente é preciso muito planejamento e estratégia para divulgar sua empresa nos sites de compra coletiva. Os empresários devem mensurar a margem de lucro e calcular o retorno sobre o investimento, analisar a capacidade de atendimento em um curto prazo, além de preparar seus empregados para receber com qualidade todas essas pessoas, já que ele depende disso para que os "clientes de oportunidade" voltem a comprar pagando o preço normal. Caso essa análise não seja feita de maneira adequada, o projeto pode não apresentar os resultados esperados e ser até prejudicial à empresa com sérios prejuízos à sua imagem e credibilidade.

\section{Metodologia}

Para se atingir o objetivo deste estudo a metodologia adotada foi composta por duas fases de coleta de dados no campo. A primeira consistiu numa pesquisa de cunho exploratório com os sites de compras coletivas, em levantamento a fim de se observar quais os tipos de empresas que mais anunciam seus bens nos mesmos. Após esse primeiro momento, uma segunda etapa da pesquisa, de cunho qualitativo, foi realizada com empresas que expõem suas marcas nos sites, com o objetivo de respondermos nossa questão problema. Realizamos entrevistas com 10 empresas que anunciam nos três principais sites de compras coletivas do estado do Rio de Janeiro: Peixe Urbano, ClickOn e Groupon, visando esclarecer pontos importantes, como o porquê de anunciar em sites como esses, entender sobre a preparação feita para o anúncio, caso tenha ocorrido, apontar possíveis problemas ocorridos durante a promoção e analisar os ganhos e a satisfação da empresa com a oferta.

O perfil e o cargo dos entrevistados variaram de acordo com o tamanho da empresa. De forma geral, em uma micro ou pequena empresa, o respondente foi o dono. Em empresas de médio porte, o 
responsável pela oferta foi o gerente (no caso, foram entrevistados gerentes de restaurantes e hotéis). Já no caso de organizações de grande porte, a pessoa escolhida para participar da pesquisa foi o gerente de marketing ou outra pessoa responsável pela área de cargo equivalente. A fim de elucidar a questão principal desse estudo, foram coletados dados de diversas empresas, de diferentes setores da economia, que tiveram suas marcas expostas em sites de compra coletiva. As questões de interesse da pesquisa foram disponibilizadas através de um roteiro com perguntas abertas, que foi passado previamente para os responsáveis pelo anúncio de cada empresa pesquisada. As entrevistas duraram de 20 (vinte) a 45 (quarenta e cinco) minutos e foram realizadas entre os dias 10 de maio e 28 de maio de 2011. Após a coleta ser feita, analisamos todas as respostas e comentários dos respondentes, usando análise de conteúdo das falas dos entrevistados.

\section{Resultados e sua análise}

A primeira etapa da pesquisa foi realizada para analisar se a maioria das empresas que anunciam em sites de compras coletivas pertence ao setor de serviços ou tem no serviço parte relevante de suas ofertas. Segundo pesquisa realizada com funcionários dos três sites que estão servindo de base para esse estudo, temos que, em média, 35\% das empresas que anunciam nesses sites são puramente produtoras e comercializadoras de serviços, 60\% são híbridas (ofertam combinação de produto mais serviço) e os outros $5 \%$ são empresas vendedoras unicamente de produtos, bens físicos tangíveis.

De acordo com a equipe comercial do site $\mathrm{ClickOn}$, os três principais setores que anunciam em seu site são: Estética, Hotelaria e Alimentos e bebidas, respectivamente. O Diretor Executivo do Groupon no Brasil, Daniel Funis, afirmou que ofertas relativas a restaurantes são de longe as mais vendidas em seu site. Em análise feita junto à equipe comercial do Peixe Urbano, a hipótese de serviços terem maior participação nesse 
segmento foi corroborada: Alimentos e bebidas, Estética e Hotelaria, nessa ordem, são as ofertas mais anunciadas. Os serviços são feitos e consumidos simultaneamente e não podem ser estocados (como bens tangíveis), e apresentam momentos de alta procura e outros de baixa procura. Para preencher essas ocasiōes em que os serviços são pouco requisitados, as empresas anunciam nos sites de compra coletiva.

A seguir abordaremos os resultados da pesquisa realizada com 10 (dez) estabelecimentos que anunciam seus bens em um dos três maiores sites de compras coletivas do estado do Rio de Janeiro. Primeiramente, quando perguntados sobre a razão para promover o anúncio (Gráfico 1), todas as dez empresas pesquisadas buscam uma forma de aumentar o número de clientes quando anunciam nessa ferramenta. Em segundo lugar, com seis citações, aparece o fato de querer tornar esses clientes de oportunidade naqueles que voltam a frequentar o estabelecimento, pagando o preço normal. De acordo com os respondentes, essa logística se dará em um momento que este cliente comprovar a qualidade do serviço oferecido. Em seguida, com quatro menções, o objetivo de gerar receita de curto prazo aparece entre as razões para fazer o anúncio, seguido da vontade de divulgar o estabelecimento (com três respostas), e, com duas respostas, o fato de preencher os horários com menor demanda.

Gráfico 1 - Respostas à pergunta: Por que anunciar em sites de compras coletivas?
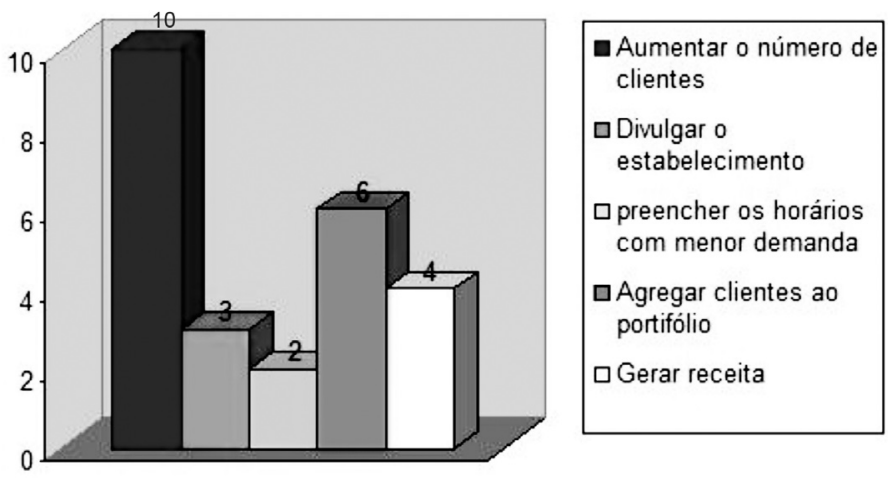

(fonte: pesquisa de campo dos autores) 
Todos esses motivos se dão pelo fato de 9 (nove) entre as 10 (dez) empresas pesquisadas serem de pequeno porte. Com um capital reduzido, elas enxergam nesses sites uma forma simples e rápida de promover seus bens e divulgar suas marcas para um grande número de pessoas. Através desse modelo de negócios, empresas de pequeno porte trocam a divulgação gerada por esses sites por descontos que, em um primeiro momento, diminuem sua margem de lucro, mas que no médio prazo pode trazer novos clientes, impulsionando o negócio.

Quando perguntados sobre como se deu a escolha do site em que a promoção foi realizada, todas as empresas pesquisadas confirmaram que os sites entraram em contato com as mesmas para oferecer um espaço em sua plataforma. Quatro das empresas entrevistadas informam que, após o contato feito pelo site, procuraram conhecer mais o setor e contatar outros sites, do mesmo porte, para analisar as ofertas. Uma das empresas informou ainda que já utilizara o serviço de um site de menor porte e que teve problemas com o desenrolar da promoção. Esta empresa hoje anuncia apenas em sites de grande porte. Através de uma entrevista realizada com um representante do site Peixe Urbano, Daniel Castro, foi confirmado que é prática do setor que os sites tomem a iniciativa de entrar em contato com as empresas para vender novas campanhas. "Nós do Peixe Urbano buscamos sempre o que há de melhor na cidade, lugares badalados ou produtos/serviços com bastante demanda, então entramos em contato com o estabelecimento e apresentamos nosso serviço.”

Em seguida foi perguntado sobre a preparação que as empresas realizavam para atender à demanda gerada pela oferta. Em 30\% dos casos foi relatado não haver nenhum tipo de preparação. Os outros $70 \%$ disseram que de algum modo se prepararam para a oferta. Em todos os dez casos, as empresas receberam um e-mail do site de compras coletivas avisando sobre possíveis consequências geradas pelo anúncio e algumas instruções básicas para as empresas. $\mathrm{O}$ gráfico 2 relata as providências tomadas pelos anunciantes. 
Gráfico 2 - Resposta à pergunta: Qual tipo de preparação foi feita?

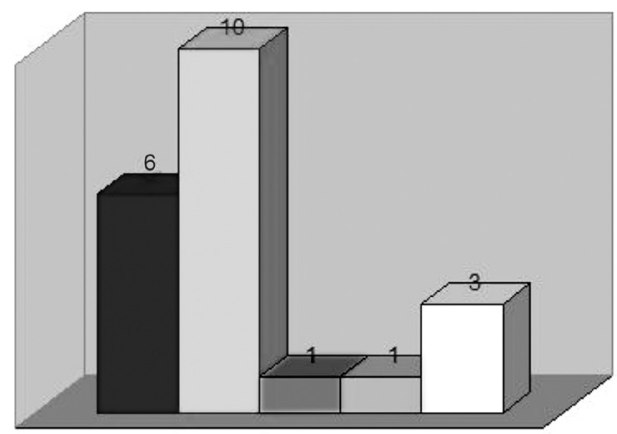

a treinamento do funcionários

$\square$ o site passou

recomendações

$\square$ gratificação extra para os

funcionários

$\square$ aumento da capacidade de atendimento

$\square$ não realizaram preparações

(fonte: pesquisa de campo dos autores)

O treinamento dos funcionários, que ocorreu em 6 (seis) casos, se deu nos seguintes quesitos: alerta sobre o aumento das ligaçóes; orientações para manter o padrão de atendimento para os clientes participantes da promoção; e as regras da promoção foram repassadas aos funcionários para que os mesmos pudessem tirar qualquer dúvida dos clientes. Aumento da infraestrutura oferecida, para suportar a demanda extra, foi feito por 1 (uma) empresa, e a gratificação dos funcionários, também com 1 (uma) citação, apareceram na lista de preparação das empresas. As outras 3 (três) empresas não realizaram nenhum tipo de preparação. Apesar das propostas de treinamento e a preparação, de uma forma geral, terem representado medidas básicas, sem nenhum investimento maior, são fatores que determinam a qualidade do serviço (PARASURAMAN, ZEITHAML; BERRY, 1985). Funcionários treinados para manter um padrão de serviço, tirar as dúvidas dos clientes e que recebem bonificação extra pelo serviço fazem com que a empresa se prontifique a aumentar a capacidade de receber clientes para melhor acomodá-los, gerando a confiabilidade no estabelecimento, a capacidade de resposta, segurança e a empatia.

Como já ocorreram problemas com ofertas anunciadas, perguntamos, em seguida, sobre possíveis problemas durante a entrega da 
oferta. Três empresas não fizeram nenhum tipo de preparação para a promoção e as mesmas 3 (três) empresas foram as que perceberam algum nível de insatisfação dos clientes quanto ao serviço apresentado (Gráfico 2). Essas insatisfações transcorrem devido tanto à demora na prestação do serviço como por incompatibilidade de datas para agendar a reserva, devido ao grande número de cupons vendidos. Vemos também que dois respondentes tiveram problemas com clientes que não leram atentamente o regulamento. $\mathrm{O}$ restante dos estabelecimentos conduziu a promoção sem a identificação de problemas relevantes.

Questionamos, então, se os clientes tinham dado algum tipo de feedback para os estabelecimentos quanto à qualidade percebida da oferta. Apenas um entrevistado revelou ter tido bastante dificuldade com a promoção, no salão Wall Coiffeur e, segundo a proprietária, o problema se deu porque anunciaram um produto que não era o ponto forte do salão e nem ficava sob o controle direto da proprietária. No caso, foi anunciado um tratamento para a pele e a dona do salão ficava responsável pela área capilar. Três respondentes detectaram retorno de clientes oriundos da oferta anunciada, satisfeitos com a experiência de serviço veiculada inicialmente no site de compras coletivas. Percebemos, através desses relatos, que é fundamental para o sucesso da promoção seguir alguns passos simples, mas que são cruciais. No caso, a empresa cometeu um erro logo no primeiro passo, que é a escolha do bem que será anunciado. A empresa deve escolher um produto/serviço que produza com excelência, pois a promoção serve exatamente como um "cartão de visita" da empresa para o cliente, e o cliente insatisfeito dificilmente retornará para uma nova experiência, ainda mais levando em conta que ele terá que pagar o preço normalmente cobrado.

Para entender alguma possível razão dos motivos das reclamações, perguntamos para as empresas se elas restringem os dias e os horários da promoção. Sabemos que os serviços não podem ser estocados, 
e estabelecimentos como hotéis, restaurantes e empresas de estética, que têm maior presença nos sites de compras coletivas, têm maior demanda durante certa parte do tempo e menor em outros. Portanto seria interessante para as empresas que restringissem essas ofertas para os momentos com demanda insipiente, visto que o cliente estaria pagando menos e não estaria "disputando" lugar com os clientes que frequentam o local pagando o preço normal. No entanto, apenas em $30 \%$ dos casos pesquisados ocorrem restrições para os horários de maior demanda, em $60 \%$ as ofertas foram livres, mediante lotação do estabelecimento, e em 10\% não houve qualquer tipo de restrição. Com isso a empresa passa a não utilizar uma grande vantagem, que é justamente ocupar os horários de menor procura. A falta dessa medida pode gerar superlotação nos horários de pico, fazendo o cliente passar por longas filas e prejudicando o atendimento, o que, por fim, acaba gerando insatisfação.

Por fim perguntamos quanto às vantagens obtidas (Gráfico 3). As empresas responderam se obtiveram algum tipo de vantagem. Todas, sem exceção, disseram ter obtido ganhos com a promoção. O principal ganho citado foi a divulgação promovida pela campanha (nove menções), seguido da adesão de novos clientes (oito), ganho de receita, citado por seis entrevistados, e, por último, com duas menções, preencher os horários com menor demanda. Portanto, visibilidade, retornos financeiros e novos clientes são as principais vantagens para quem utiliza sites de compras coletivas, o que indica que as empresas efetivamente recebem os benefícios que buscam ao anunciar seus serviços em sites de compras coletivas. Uma vantagem mostrada pelo site, mas que nenhuma empresa pesquisada citou como relevante, foi o fato do estabelecimento não ter gastos financeiros imediatos com a oferta: teria margem de lucro reduzida ou mesmo nula, que é trocada pela divulgação que será feita. Parece ser indício do pouco conhecimento das empresas anunciantes sobre o modelo de negócios, em que vislumbram a possibilidade de atrair novos clientes no curto 
prazo e de maneira relativamente simples, mas negligenciam a análise comparativa do uso de outras formas de divulgação.

Gráfico 3 - Resposta à pergunta: A empresa obteve ganhos ao anunciar no site? Quais?

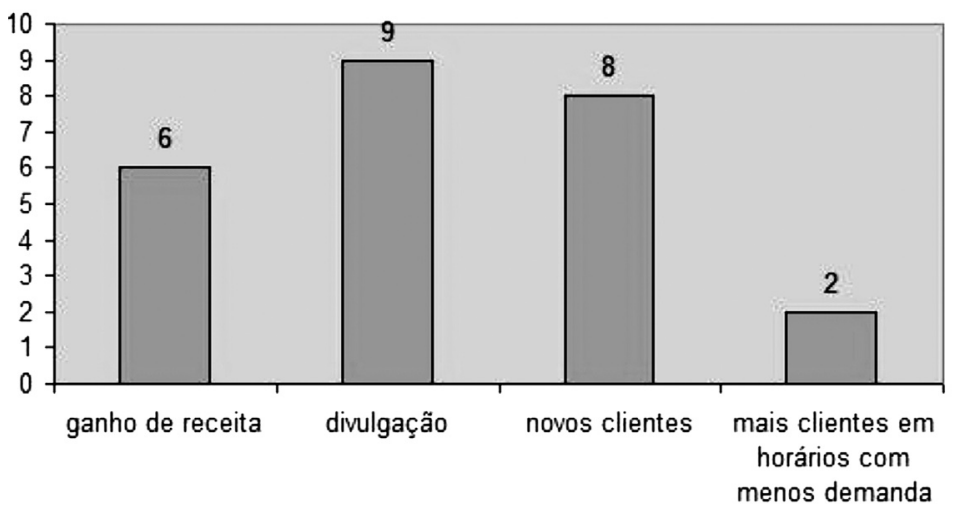

(Fonte: pesquisa de campo dos autores)

Por fim, questionamos se as empresas voltariam a anunciar em sites de compras coletivas. Oito das dez empresas pesquisadas informaram que pretendem anunciar novamente. Dessas, cinco possuem ofertas regulares, que são feitas em determinados períodos de tempo (por exemplo, a cada três meses). Das duas empresas que disseram que não pretendem lançar novas ofertas, uma ainda está analisando os resultados da primeira oferta, e a outra afirmou que a empresa teve mais problemas do que ganhos com a promoção.

\section{Conclusões}

Esse estudo exploratório investigou a existência de lacunas entre os objetivos pretendidos e os efetivamente alcançados por empresas ao anunciar em sites de compras coletivas. Nossos resultados apontam que há um equilíbrio entre estas expectativas e os resultados efetivamente alcançados, o que aponta para o crescimento na demanda por tais serviços por parte dos anunciantes. Apesar desta perspectiva 
favorável, foram detectados pontos que devem ser ajustados, principalmente em direção à maior informação para o consumidor, visando às regras e funcionalidades dos sites e suas promoções. Outro ponto seria aprofundar, por parte dos anunciantes, a análise sobre a seleção dos serviços a anunciar; preparação interna para a realização da oferta (avaliar desde se o estabelecimento está apto a utilizar um site como meio de comunicação, até o cálculo do número máximo de cupons que poderão ser vendidos sem que haja superlotação do local e prejuízos para a empresa); os sites a escolher; e fatores que impactam a satisfação do consumidor, especialmente para cultivar a imagem positiva no primeiro contato. Como sugestôes futuras, esse estudo pode ser desdobrado através da investigação sobre a percepção dos clientes quanto aos serviços apresentados pelas empresas que anunciam em sites de compra coletiva.

\section{Referências}

ARAÚJO, Rodolfo. As compras coletivas vão acabar? . Rio de Janeiro 29 de março. de 2011. Disponível em: < http://www.administradores.com.br/informe-se/artigos/ as-compras-coletivas-vao-acabar/53703/ >. Acesso em: 28 maio 2011.

BATESON, John; HOFFMAN, Douglas. Marketing de Serviços. São Paulo: Bookman, 2001.

BEATTY, S.; FERREL, E. Impulsive buying: modeling its precursors. Journal of Retailing, v. 74, n. 2, p. 169-191, 1998.

BLOG DO E-COMMERCE. O criador da compra coletiva. Rio de Janeiro 20 de janeiro. 2011. Disponível em: < http://www.blogdoecommerce.com.br/criadorcompra-coletiva/ >. Acesso em: 20 mar. 2011

CALLEGARI, Lucas. Compras coletivas alcançam 61\% dos internautas brasileiros. Rio de Janeiro. 22 de abril de 2011. Disponível em: < http://idgnow.uol.com.br/ internet/2011/03/22/pesquisa-compras-coletivas-alcancam-61-dos-internautasbrasileiros/ >. Acesso em: 22 abr. 2011.

FINKLE, Jim. Groupon fará oferta de ações para levantar até US\$ 950 milhões. Rio de Janeiro. 29 de dezembro de 2010. Disponível em: <http://exame.abril. 
com.br/mercados/noticias/groupon-fara-oferta-de-acoes-para-levantar-ate-us-950milhoes>. Acesso em: 18 mar. 2011.

GAVIOLI, Guilherme. Compra coletiva. Rio de Janeiro 20 de novembro. 2010.

Disponível em: <http://ecommercenews.com.br/glossario/o-que-e-compra-coletiva>. Acesso em: 18 mar. 2011.

GRONROOS, Christian. Marketing - Gerenciamento e Serviços - A competição por serviços na Hora da Verdade. 3. ed. Rio de Janeiro: Campus, 2009.

KOTLER, Philip. ARMSTRONG, Gary. Princípios de Marketing. 9. ed. São Paulo: Prentice Hall, 2006.

KOTLER, Philip. KELLER, Kevin Lame . Administração de Marketing. 12. ed. São Paulo:Ed. Editora Prentice Hall, 2006.

MACÁRIO, Talita. Compras coletivas: O que esperar em 2011. Rio de Janeiro. 30 de novembro de 2010. Disponível em: <http://blog.jetecommerce.com.br/mercado/ compras-coletivas-o-que-esperar-em-2011>. Acesso em: 16 mar. 2011.

MENEZES, Bruno. Até que ponto as compras coletivas ajudam. Rio de Janeiro 27 de agosto de 2010b. Disponível em: <http://www.openbuy.com.br/artigo/ate-queponto-as-compras-coletivas-ajudam>. Acesso em: 4 abr. 2011.

MENEZES, Bruno. Compra Coletiva - estratégia de web marketing. Rio de Janeiro 07 de dezembro de 2010a. Disponível em: <http://www.openbuy.com.br/ artigo/compra-coletiva-estrategia-de-web-marketing>. Acesso em: 3 abr. 2011. OSCAR, Naiana. Empresas têm prejuízo com sites de compra coletiva. Rio de Janeiro. 29 de abril de 2011. Disponível em: <http://www.estadao.com.br/ estadaodehoje/20110329/not_imp698619,0.php>. Acesso em: 19 mar. 2011. PARASURAMAN, A.; ZEITALM, V.; BERRY, L. e. Serviços de marketing competindo através da qualidade. São Paulo: Editora Maltese Norma, 1992.

ROOK, D. W. The Buying Impulse. Journal of Consumer Research. n.14, p 189-199, 1987.

SÁ, Silvia de. Preconceito gera problemas com compras coletivas. Rio de Janeiro. 2 de fevereiro de 2011. Disponível em: <http://exame.abril.com.br/marketing/ noticias/preconceito-gera-problemas-com-compras-coletivas $>$. Acesso em: 20 mar. 2011. 
SCHNOOR, Tatiana. Brasil já tem 1,2mil sites de compras coletivas, aponta e-bit. Rio de Janeiro 22 de março de 2011. Disponível em: <http://oglobo.globo.com/ economia/mat/2011/03/22/brasil-ja-tem-1-2-mil-sites-de-compras-coletivas-apontabit-924064508.asp>. Acesso em: 1 abr. 2011.

THE BEST. Confira os 37 sites de compras coletivas mais relevantes. Rio de Janeiro 1 de novembro. 2010. Disponível em: <http://www.thebest.blog.br/confiraos-37-sites-de-compra-coletiva-mais-relevantes-no-brasil/>. Acesso em: 16 mar. 2011.

TODESCHINI, A. Entrevista com Andrew Mason - fundador do Groupon. Rio de Janeiro, 4 de outubro de 2010. Disponível em: <http://ecommercenews.com.br/ artigos/entrevistas-artigos-3/entrevista-com-andrew-mason-groupon>. Acesso em: 25 mar. 2011.

VITULLI, Rodrigo. Sites de compras coletivas dão exemplo de empreendedorismo na Campus Party. Rio de Janeiro. 4 de abril de 2011. Disponível em: < http:// tecnologia.uol.com.br/ultimas-noticias/redacao/2011/01/20/sites-de-comprascoletivas-dao-licoes-de-empreendedorismo-na-campus-party-2011.jhtm>. Acesso em: 4 abr. 2011. 